\title{
Effect of cost awareness on the utilization of laryngeal mask airway among anesthesiology residents
}

\author{
Michael Stuart Green, Sheldon B. Gomes, Kelly A. Machovec, Parmis Green \\ Drexel University College of Medicine/Hahnemann University Hosptial, Philadelphia, PA, United States \\ Correspondence: Michael Stuart Green. Address: Department of Anesthesiology, Drexel College of Medicine, 245 North \\ 15th Street, Suite 7502, Philadelphia, PA, United States. E-mail: Michael.green@drexelmed.edu \\ Received: December 12, 2012 \\ Accepted: March 19, 2013 \\ Online Published: April 6, 2013 \\ DOI : $10.5430 /$ jha.v2n3p113 \\ URL: http://dx.doi.org/10.5430/jha.v2n3p113
}

\begin{abstract}
Introduction: Knowledge of cost perception is the primary step towards determining the role cost plays in decision making. We examined perception of cost and utilization. We tried to determine reasons for choosing pieces of equipment and tested the effect of cost awareness. We hypothesized altered utilization patterns in favor of a less expensive product.

Methods: We conducted a single blind prospective study examining the perceptions of laryngeal mask airway (LMA) cost among residents. The study tested whether cost awareness would alter utilization. The price was altered without residents' knowledge to ensure recognition of a price difference. Utilization before and after price labeling was compared.

Results: The survey results showed when asked specifically 'does cost influence your choice of LMA?' 56\% of the residents answered 'No'. Only 2 out of 23 resident responses to the question 'how much does an LMA cost' fell within a $50 \%$ range of its approximate cost of $\$ 8$. When asked 'if two products are equivalent, would you choose the cheaper one?' all residents answered 'Yes'.

Prior to price labeling, LMA selection 8.25\% GREEN and 91.75\% CLEAR. After price labeling, selection of LMA's was 24.27\% GREEN and 75.73\% CLEAR LMA's. There was a significant difference between the utilization of GREEN and CLEAR LMA's before and after price labeling.

Conclusion: This prospective single blind study on how cost awareness effects LMA selection showed altered selection following price labeling towards lower cost products. Focusing on cost awareness may have an impact on the future utilization and health care expenses.
\end{abstract}

\section{Key words}

Laryngeal masks, Costs and cost analysis, Utilization, Education

\section{I ntroduction}

Consideration of cost in patient care is one of the tenets of the Systems Based Practice Core Competency put forth by the ACGME $^{[1]}$. It requires residents to demonstrate an awareness of the larger system of health care and the ability to effectively call on system resources to provide care that is of optimal value ${ }^{[1]}$. Knowledge of residents' perceptions of cost is the primary step towards determining the role that cost plays in their clinical decision making process and can be a useful tool to identify possible deficiencies in residency training. 
Multiple factors play into decision making in anesthesiology. Choice of anesthetic technique involves the intra-operative and post-operative effects of that technique, as well as length of stay and return to daily activities ${ }^{[2]}$. Further, choice of a specific drug or device is shaped by previous experience, current literature, influence of pharmaceutical advertisements, convenience, ease of use, perceived side effects, and cost.

Cost cannot be the sole determinant of anesthetic technique; however, given two nearly equal options, cost must enter into the decision making process. We designed a study to examine perception of cost and resource utilization among residents of a tertiary care Anesthesiology training program. We utilized a survey to determine residents' self-reported reasons for choosing one of two pieces of equipment, then tested whether cost awareness altered that decision. We hypothesized that residents would alter selection in favor of a less expensive product when presented with price data.

\section{Materials and methods}

We conducted a single blind prospective study examining the perceptions of laryngeal mask airway (LMA) cost among the residents at a tertiary care teaching hospital. The study was approved by the local Institutional Review Board. We conducted a literature review on pub med using keywords 'cost-consciousness', 'cost awareness', 'price-labeling', and 'anesthesia provider decision making'.

At the start of the study, residents completed a brief survey designed to assess their cost awareness and perceptions of cost-consciousness. The survey questions are presented in Table 1. This survey was conducted using Survey Monkey ${ }^{\mathrm{TM}}$ and the following link was emailed to all residents in the anesthesiology program: http://www.surveymonkey.com/s/ SNGLJLD. The program consists of 24 residents and all residents except the one involved in the study were asked to respond within a week.

Next, the study tested whether cost awareness in the form of price labeling would alter LMA selection. LMA selection prior to price labeling was obtained retrospectively from anesthesia departmental inventory records. Cases meeting the following criteria were included in the study: adult patients ( $>18$ years old) receiving general anesthesia, use of an LMA as the primary airway device, and involvement of a resident physician. LMA use for airway rescue purposes was not included.

In each operating room, a partitioned box was placed adjacent to the airway supplies, readily accessible to the resident. One side of the box contained single use sterile LMAs (GREEN) in sizes 3, 4, and 5. The other side of the box contained single use sterile LMAs (CLEAR) in sizes 3, 4, and 5. At the beginning of each day ample amounts of each type of LMA were placed in the box. Price labels were placed on the partitioned LMA box: $\$ 8.50$ for GREEN and \$13.75 for CLEAR. The actual cost of the GREEN is $\$ 8.50$ and CLEAR is $\$ 7.65$. The price was altered with IRB's approval, but without residents' knowledge, to ensure the residents' recognition of a price difference and to maximize the impact of that difference. Following LMA usage residents filled out a simple form with a check box to identify each LMA used and forms were collected at the end of the day. The selection of the two types of LMA's before and after price labeling was compared.

\section{Statistical analysis}

Data entry and analysis were performed with SPSS (Version 11.0., Chicago, United States of America). The response from the resident's survey was analyzed; percentages were obtained and compared with Chi-Square Test. Cross tabulation was done to determine if there is any association between the survey results and LMA utilization. Chi- square values and $p$-values were obtained. The number and percentages of different types of LMAs which were used before and after cost labeling were obtained and statistically significant differences were determined by $2 \times 2$ Chi-Square Test ${ }^{[3]}$. 
Table 1. LMA Utilization Survey Results ( $\mathrm{N}=23)$

\begin{tabular}{|c|c|c|c|}
\hline \multirow{2}{*}{ Survey Questions } & \multicolumn{3}{|l|}{ Results } \\
\hline & n (\%) & $\begin{array}{l}\text { Chi-square } \\
\text { statistics (df) }\end{array}$ & $p$ \\
\hline \multicolumn{4}{|l|}{ 1. Which LMA would you chose for your patients? } \\
\hline Ambu Aura-once (GREEN) & $3(13.0)$ & \multirow{3}{*}{$10.78(2)$} & \multirow{3}{*}{0.005} \\
\hline LMA Unique (CLEAR) & $15(65.2)$ & & \\
\hline I would use them equally & $5(21.8)$ & & \\
\hline \multicolumn{4}{|l|}{ 2. Why did you choose this LMA? } \\
\hline Ease of Insertion & $4(17.4)$ & \multirow{5}{*}{$5.48(4)$} & \multirow{5}{*}{$>0.05$} \\
\hline Availability, better ease of access & $1(4.3)$ & & \\
\hline More comfortable with use of this LMA than the other LMA & $5(21.7)$ & & \\
\hline Poor clinical experience with the alternative LMA & $5(21.7)$ & & \\
\hline I have no preference between these two LMAs & $8(34.9)$ & & \\
\hline \multicolumn{4}{|l|}{ 3. Are these two LMAs equivalent? } \\
\hline Yes & $13(56.5)$ & \multirow{2}{*}{$0.39(1)$} & \multirow[t]{2}{*}{$>0.05$} \\
\hline No & $10(43.5)$ & & \\
\hline \multicolumn{4}{|l|}{ 4. How much does an LMA cost } \\
\hline Accurate response within a 50\% range of the cost (\$4-12) & $2(8.7)$ & \multirow[t]{2}{*}{$15.70(1)$} & \multirow[t]{2}{*}{$<0.001$} \\
\hline Outside of the $50 \%$ range & $21(91.3)$ & & \\
\hline \multicolumn{4}{|l|}{ 4a. Estimation of price } \\
\hline Less than $\$ 10$ & $1(4.3)$ & \multirow{5}{*}{$7.60(3)$} & \multirow{5}{*}{$>0.05$} \\
\hline$\$ 11$ to $\$ 50$ & $8(34.7)$ & & \\
\hline$\$ 51$ to $\$ 100$ & $5(21.7)$ & & \\
\hline$\$ 101$ to $\$ 200$ & $1(4.3)$ & & \\
\hline No response & $3(13.0)$ & & \\
\hline \multicolumn{4}{|l|}{ 5. Does cost influence your choice of LMA? } \\
\hline Yes & $10(43.5)$ & \multirow{2}{*}{$0.39(1)$} & \multirow{2}{*}{$>0.05$} \\
\hline No & $13(56.5)$ & & \\
\hline \multicolumn{4}{|l|}{ 6. Are better products more expensive? } \\
\hline Yes & $7(30.4)$ & \multirow{2}{*}{$3.52(1)$} & \multirow[t]{2}{*}{$>0.05$} \\
\hline No & $16(69.6)$ & & \\
\hline \multicolumn{4}{|c|}{ 7. If two products are equivalent would you choose the cheaper product? } \\
\hline Yes & $23(100.0)$ & & \multirow[b]{2}{*}{ - } \\
\hline No & 0 & & \\
\hline
\end{tabular}

\section{Results}

All 23 Anesthesiology residents currently enrolled in the program (except the one involved in the study) completed the survey on LMA cost awareness prior to price labeling. The survey results are presented in Table 1. Nine (39.2\%) residents were from Clinical Anesthesia year 1 (PGY2) and 7 (30.4\%) residents each from Clinical Anesthesia year 2 (PGY3) and 
Clinical Anesthesia year 3 (PGY4). Significantly more residents reported a preference for LMA CLEAR compared to GREEN ( $p=0.005)$. There was no significant reason for choosing a certain LMA in the survey results. When asked specifically 'does cost influence your choice of LMA?' 56\% of the residents answered 'No'. Only 2 out of 23 resident responses to the question 'how much does an LMA cost' fell within a 50\% range of its approximate cost of $\$ 8(p<0.001)$, indicating a significant majority were unaware of the cost of LMA. However, when asked 'if two products are equivalent, would you choose the cheaper one?' all residents answered 'Yes'.

\section{Results after price labeling}

After collecting the survey results, price labels were placed to assess the impact of price labeling on resident choice of two equivalent LMA products. LMA choice prior to price labeling was obtained retrospectively from inventory records over the prior 4 months. Prior to price labeling, the type of LMA chosen was distributed between $8.25 \%$ GREEN and 91.75\% CLEAR LMA's. After price labeling, the choice of LMA was distributed between 24.27\% GREEN and 75.73\% CLEAR LMA's. There was a significant difference $(p<0.001)$ between the selection of GREEN and CLEAR LMA's by residents before and after price labeling (Table 2).

Table 2. LMA Utilization Before and After Cost Labeling

\begin{tabular}{lllll}
\hline & Types of LMA & Type of LMA & Chi-Square value & $p$ \\
\hline MA Utilization & GREEN & CLEAR & & \\
After Cost Labeling & $25(24.27 \%)$ & $78(75.73 \%)$ & & $<0.001$ \\
Before Cost Labeling & $90(8.25 \%)$ & $1000(91.75 \%)$ & 27.71 & \\
\hline
\end{tabular}

\section{Discussion}

Cost awareness is a vital component of the 'Systems based practice' Core Competency set forth by the ACGME. This study assessed residents' perceptions of LMA cost. The subsequent intervention (price labeling) aimed to ensure the residents were aware of the cost of two similar LMA products and tested whether this awareness will then influence their selection.

Previous studies have documented the lack of cost awareness among anesthesia providers, particularly in relation to anesthetic drug use. Survey responses from anesthesia providers tend to underestimate the cost of more expensive products while overestimating the cost of cheaper items ${ }^{[4,5]}$. The variance in cost estimation has been shown to be greater in less experienced anesthesia trainees when compared to Clinical Anesthesia year 3 and attendings ${ }^{[6]}$. This reiterates the importance of early education regarding costs during anesthesia residency training. We conducted a survey among residents at all levels of training with regards to the cost of an LMA - a piece of equipment that is an integral part of their training and therefore representative of a more global picture of cost awareness during residency. Our survey proved that a majority of residents were unaware of the cost of an LMA (within a 50\% range of its approximate cost $(2 / 23, p<0.001)$ ). It is no surprise then that when asked directly 'does cost influence your choice of LMA?' 56\% responded 'No'. A similar survey of anesthesia providers (Trainees and Consultants) at three teaching hospitals in the UK to assess anesthetic drug cost awareness found $36 \%$ of the estimates within $50 \%$ of the true price and concluded that cost awareness is lacking among anesthesia providers ${ }^{[7]}$. The findings of our survey, which looked exclusively at trainees, were more alarming, in that only $8 \%$ of the estimates were within the $50 \%$ range. However, when asked 'if two products are equivalent, would you choose the cheaper one?' all residents answered 'Yes'. This suggests that there is room for improvement with regards to 
cost consciousness during residency training. The more important question however, is if residents are made aware of cost, will this cost awareness alter their practice?

The next part of the study aimed at answering this question. The intervention, in the form of price labeling of two equivalent products, makes residents aware of cost and tests whether this knowledge alters their practice. Price labeling has been shown to be effective in improving awareness among anesthesia providers ${ }^{[8]}$. However, the impact of price labeling on product selection may be mixed. Lin et al found that price labeling reduced expenditures on more expensive muscle relaxants while Horrow et al found that price labeling had a minimal impact on clinicians' drug usage ${ }^{[9,10]}$. The results of price labeling in our study indicate a significant increase in the use of the lower price labeled LMA suggesting that cost awareness does impact residents' practice.

Our study is unique in that it assesses residents' self-reported perceptions of cost relating to a piece of equipment that is integral to their training and then tests the impact of price labeling on their practice. It aims to identify the lack of cost awareness which may be representative of a more global deficiency in residency training and whether price labeling can address this deficiency.

Some of the strengths of the study are that residents were blinded to the study purpose and the actual cost of the LMA. They had full autonomy in making their choice of LMA and equal access to 3 different sizes of both types of LMA's. This type of information may lead to more robust studies on operating room cost and outcomes. The educational importance of trainees on cost awareness and lack of cost awareness is highlighted.

A disadvantage that is inherent to a study of this kind is that residents already have a pre-existing preference for one type of product which may then continue to influence their choice even after becoming aware of cost. We attempted to get a clearer picture of whether one specific bias of this nature existed by asking residents why they picked one type of LMA over the other in the pre-price labeling survey. None of the various options provided were statistically significant suggesting that there was no single, uniform reason for preferring one type of LMA.

The preference for CLEAR LMA's in the pre-intervention survey would have been more of a concern if there was no significant increase in selection of GREEN LMA's after price labeling - i.e.: a pre-existing bias unrelated to cost in favor of CLEAR LMA's could have prevented an increase in utilization of GREEN LMA's. Theoretically, if such a bias had been eliminated, it would if anything, increase the impact that price labeling would have on choosing the lower priced GREEN LMA.

There was also no way to prevent residents from researching the true cost of an LMA and then preventing this information from affecting their choice. The answer to the survey question 'does cost influence your choice of LMA?' in which 56\% answered 'No' makes it less likely though not impossible that residents would have researched the actual price.

In conclusion, this prospective single blind study on how cost awareness effects LMA utilization in anesthesia residents showed improved knowledge of cost does alter LMA selection in favor of a cheaper product. Development of educational materials focusing on cost awareness may have a large impact on the future utilization and health care expenses.

\section{References}

[1] Stewart MG. Core Competencies, 2001:http://www.acgme.org/acwebsite/RRC_280/_corecomp.asp.

[2] Wetchler BV. Economic impact of anesthesia decision making: they pay the money, we make the choice. J Clin Anesth. 1992; 4: 20S-4S. http://dx.doi.org/10.1016/0952-8180(92)90014-R

[3] Dupont WD, Plummer WD, Jr. Power and sample size calculations. A review and computer program. Control Clin Trials. 1990; 11: 116-28. http://dx.doi.org/10.1016/0197-2456(90)90005-M 
[4] Bailey CR, Ruggier R, Cashman JN. Anaesthesia: cheap at twice the price? Staff awareness, cost comparisons and recommendations for economic savings. Anaesthesia. 1993; 48: 906-9. PMid:8238838 http://dx.doi.org/10.1111/j.1365-2044.1993.tb07428.x

[5] Schlunzen L, Simonsen MS, Spangsberg NL, Carlsson P. Cost consciousness among anaesthetic staff. Acta Anaesthesiol Scand. 1999; 43: 202-5. PMid:10027029 http://dx.doi.org/10.1034/j.1399-6576.1999.430214.x

[6] Wax DB, Schaecter J. Cost awareness among anesthesia practitioners at one institution. J Clin Anesth. 2009; 21: 547-50. PMid:20122584 http://dx.doi.org/10.1016/j.jclinane.2008.12.029

[7] Egan T, Varveris DA, Carse J, Smart NG. Anaesthetic drug cost awareness. Anaesthesia. 2007; 62: 307-8. http://dx.doi.org/10.1111/j.1365-2044.2006.04944_9.x

[8] Snyder-Ramos SA, Bauer M, Martin E, Motsch J, Bottiger BW. Accessible price lists at the anaesthesiologist's workplace enhance cost consciousness as a part of process and cost optimization. Anaesthesist. 2003; 52: 154-61. PMid:12624701 http://dx.doi.org/10.1007/s00101-002-0413-7

[9] Horrow JC, Rosenberg H. Price stickers do not alter drug usage. Can J Anaesth. 1994; 41: 1047-52. PMid:7828250 http://dx.doi.org/10.1007/BF03015652

[10] Lin YC, Miller SR. The impact of price labeling of muscle relaxants on cost consciousness among anesthesiologists. J Clin Anesth. 1998; 10: 401-3. http://dx.doi.org/10.1016/S0952-8180(98)00053-1 